\title{
Erratum: The Implications of Research on Expertise for Curriculum and Pedagogy
}

\author{
David F. Feldon
}

Published online: 13 January 2007

(C) Springer Science + Business Media, LLC 2007

The description of the 1993 study by Crandall and Getchell-Reiter contained an incorrect explanation of the methodology. During initial interviews with participants, researchers did not provide any guidance regarding the type of detail to provide. Therefore, the sentence reading "Interviewers emphasized the need for the nurses to be as specific as possible about assessment parameters, diagnostic cues, and clinical judgments that they used," should be omitted.

The online version of the original article can be found at: http://dx.doi.org/10.1007/s10648-006-9009-0.

D. F. Feldon $(\bowtie)$

Department of Educational Studies, College of Education, University of South Carolina,

1801 Shadowood Drive, Columbia, SC 29212, USA

e-mail: feldon@gwm.sc.edu 